\title{
Flame retardant poly(lactic acid) biocomposites reinforced by recycled wool fibers - Thermal and mechanical properties
}

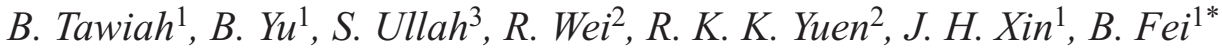 \\ ${ }^{1}$ Institute of Textiles and Clothing (ITC), The Hong Kong Polytechnic University, Hong Kong, China \\ ${ }^{2}$ Department of Civil and Architectural Engineering, City University of Hong Kong, Kowloon, Hong Kong, China \\ ${ }^{3}$ Department of Mechanical Engineering, The Hong Kong Polytechnic University, Hong Kong, China
}

Received 15 January 2019; accepted in revised form 10 March 2019

\begin{abstract}
The inherently poor flame retardancy and comparatively low tensile strength of poly(lactic acid) (PLA) have limited its wide adoption as alternative 'green' engineering plastic in many fields. This manuscript reports the synthesis of a new phosphorus flame retardant - phenylphosphonic 3(2-aminobenzothiazole) (P-TAB) and its combination with recycled short wool fibers (WF) for improving the flame retardancy and the mechanical properties of PLA. Fourier transform infrared (FTIR), ${ }^{1} \mathrm{H}$, and ${ }^{13} \mathrm{C}$ nuclear magnetic resonance (NMR) spectra proved that P-TAB was effectively synthesized. Considerable reductions in heat release rate, total heat released, $\mathrm{CO}$ and $\mathrm{CO}_{2}$ produced were attained with $3 \mathrm{wt} \% \mathrm{P}-\mathrm{TAB}$ and various $\mathrm{WF}$ loadings. The fire performance index (FPI), and fire growth index (FGI) improved by 38.2 and $48.1 \%$ respectively. The composite achieved a V-0 rating at $20 \mathrm{wt} \% \mathrm{WF}$ loading and an LOI value of $28.5 \%$. TG-IR results showed substantial reductions in evolved gaseous products. The tensile strength and Young's modulus improved significantly with the increasing content of WF in the composite.
\end{abstract}

Keywords: polymer composites, flame retardant, cone calorimeter, fiber reinforcement, pyrolysis products

\section{Introduction}

Polymer composites (PCs) are designed to achieve properties beyond those attainable by homopolymers [1-4]. Among the different classes of PCs, fiber reinforced polymer composites (FRPCs) with thermoplastic polymers are particularly useful in the production of different engineering products due to their light weight and high mechanical properties [5-8]. The most preferred reinforcement material for PCs are often natural fibers because of their biodegradability, low cost, and excellent mechanical properties [9-11]. PCs find applications in different fields including automotive and the aviation industry, buildings and construction, and windmills as blades [9, 12-15]. Considering the high-end engineering applications of PCs, the need for bio-based FRPCs with improved flame resistance and excellent mechanical properties cannot be overemphasized $[9,16,17]$. PLA is a vital bioplastic with excellent properties, but the issue of high flammability and low thermo-mechanical properties has made it inferior compared to the petrochemically derived plastics $[18,19]$. This has limited its applications where high tensile strength and flame resistance is required $[20,21]$. Therefore, a mechanically robust FR PLA composite is proposed using phosphorus-nitrogen-sulfur containing FR reinforced by recycled short wool fibers. In this way, a bio-based PLA PC with superior FR performance and exceptional tensile strength can be obtained with properties that can match or exceed the performance 
of the traditionally known petrochemically derived PCs.

Wool, a protein-based animal fiber with rich nitrogen and sulfur content $[22,23]$ possess inherent flame resistance capabilities and does not drip when burning $[24,25]$. Also, wool has unique properties such as high ignition temperature, low heat of combustion and a high LOI (ca. 25.2\%) [26]. Its flame resistance performance is linked to the dehydration predisposition of the sulfur-containing amino acids and the release of inert nitrogen oxides during combustion leading to the formation of intumescent chars [26-28]. The amino acids and abundant sulfur in WF catalyzes dehydration and the production of char which can limit the possibility of melt dripping commonly associated with PLA. Beyond the inherent FR properties of wool fiber (WF), it also possesses high tensile strength due to its microfibrillated network structure; hence its combination with thermoplastics in recent years for simultaneous mechanical strength and flame resistance enhancement for PCs in recent years [22, $24,29,30]$. In this manuscript, the conversion of recycled WF for reinforcement of bioplastic $\mathrm{PC}$ is proposed together with a new FR - phenylphosphonic tri(2-aminobenzothiazole) (P-TAB) to reduce the incidence of WF waste in the environment.

Phosphorus $(\mathrm{P})$ containing FRs are particularly important due to their high efficiency, low loading, and less corrosive effect on equipment during processing and combustion $[31,32]$. As a result, different $\mathrm{P}$ containing FRs have been synthesized and applied to different polymers over the years [33, 34]. Recently, $P$ containing FRs with a significant amount of nitrogen $(\mathrm{N})$ and sulfur $(\mathrm{S})$ are deemed to further enhance the condensed phase FR chemistry of polymeric materials during combustion $[35,36]$. The P-N-S containing FRs possess unique properties because they function actively in both the condensed and the gas phases to change the typical decomposition route of polymers [36]. Typically, the S moiety degenerates into sulfonic acids during the pyrolysis process to augment and promote char formation of P moiety in the condensed phase. The $\mathrm{N}$ component releases inert nitrogen oxides that reduces the burning rate of the polymer in the gas and the condensed phase. Despite the inherent FR performance and high tensile strength of WF, its application as fiber reinforced PLA composites (FRPC) with a new P-N-S containing FR has rarely been reported. P-N-S containing substances are generally eco-friendly because they are the main constituents of most manure and plants nutrients, and therefore may not cause environmental pollution in landfill sites, considering the fact that PLA is also $100 \%$ compostable $[37,38]$.

This manuscript reports the design and synthesis of a new FR containing a significant amount of P-N-S and its combination with recycled short WF for simultaneous FR and tensile strength enhancement of PLA biocomposites. The FR was synthesized using the $\mathrm{A}_{3}+\mathrm{B}_{1}$ mechanism and compounded with PLA and WF by means of solvent mixing and compression molding approaches to produce FRPCs. The thermal, crystallization and mechanical FR properties of the FRPCs were investigated extensively, and the FR mechanism was elucidated.

\section{Experimental}

PLA granules (Bioplus 6201D) was supplied by NatureWorks, 15305 Minnetonka Blvd., Minnetonka, USA. Phosphoryl chloride $\left(\mathrm{POCl}_{3}\right)(99.5 \%)$, pyridine$\mathrm{d}_{5}$, and non-ionic detergent octylphenoxypolyethoxyethanol (NP-40) were supplied by Sigma Aldrich (Germany). 2-Aminobenzothiazole (ABT) (97\%), sodium sulfate anhydrous, trimethylamine (TEA), sodium carbonate, and anhydrous tetrahydrofuran (THF) were purchased from Acros Organics (USA). Waste wool fiber (WF) was supplied as a gift by Hengyuanxiang (Group) Co., Ltd, Shanghai, China. The WF was pretreated before mixing with PLA/PTAB composites.

\subsection{Pretreatment of recycled wool fiber}

Waste WF was scoured in $1 \mathrm{~g} / 1 \mathrm{Na}_{2} \mathrm{CO}_{3}$ and $1 \mathrm{~g} / 1$ $\mathrm{NP}-40$ non-ionic detergent at $60^{\circ} \mathrm{C}$ for $30 \mathrm{~min}$ to remove dirt. WF was rinsed successively in warm and cold water, squeezed, and dried at room temperature. WF was then cut into an average length of $2-3 \mathrm{~mm}$ and homogenized for $10 \mathrm{~min}$. The homogenized WF was further dried in a vacuum oven at $100^{\circ} \mathrm{C}$ overnight to attain constant weight before compounding.

\subsection{Synthesis of phenylphosphonic 3(2-aminobenzothiazole) (P-TAB)}

P-TAB was synthesized according to Figure 1. 2Aminobenzothiazole $(0.3 \mathrm{~mol})$ was dissolved in $40 \mathrm{ml}$ anhydrous THF, discharged into a round bottom flask under stirring in an ice bath during which $0.3 \mathrm{~mol}$ TEA was added under low humidity ( $R H$ 14). POCl $0.1 \mathrm{~mol}$ in $10 \mathrm{ml}$ anhydrous THF was added dropwise, and the reaction proceeded in an ice bath for 


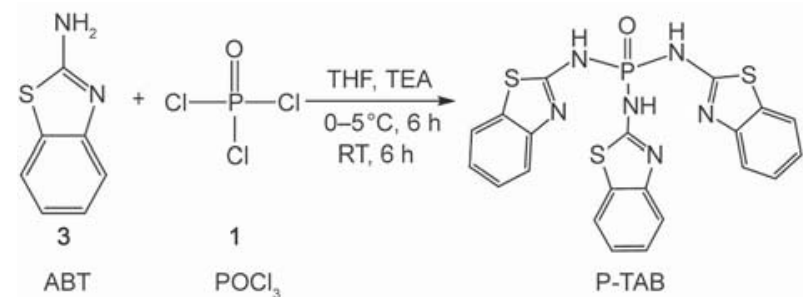

Figure 1. Synthesis of phenylphosphonic 3(2-aminobenzothiazole) (P-TAB).

$6 \mathrm{~h}$ and then at room temperature for another $6 \mathrm{~h}$. The product was washed severally with THF and DI water to remove the unreacted monomers, and the triethylamine hydrochloride produced until $\mathrm{pH}$ 6.5-7 was attained. The pure compound was dried over sodium sulfate anhydrous for $24 \mathrm{~h}$ and then in a vacuum oven at $60^{\circ} \mathrm{C}$ for $24 \mathrm{~h}$ to obtain a product yield of $83.7 \%$. The product (P-TAB) $\left(M_{\mathrm{W}} 494.55\right)$ was characterized by ${ }^{1} \mathrm{H}$ NMR (400 MHz, Pyr) $\delta 9.25$ (d, $J=8.0 \mathrm{~Hz}, 3 \mathrm{H}), 9.23(\mathrm{~d}, J=7.9 \mathrm{~Hz}, 3 \mathrm{H}), 9.15$ (s, $J=$ $7.8 \mathrm{~Hz}, 3 \mathrm{H}), 8.82-8.74(\mathrm{~m}, 3 \mathrm{H}), 8.69(\mathrm{~m}, 3 \mathrm{H}), 8.59$ $8.52(\mathrm{~m}, 3 \mathrm{H}) .{ }^{13} \mathrm{C}$ NMR (101 MHz, Pyr) $\delta=169.31$, $154.75,133.30,127.35,122.95,122.59,120.01$.

\subsection{Preparation of PLA/P TAB/WF composites}

PLA/P-TAB/WF composites were prepared by the combinatory solvent mixing, and the hot compression molding approach similar to the literature [39]. A quantity of P-TAB (see Table 1) was dispersed in $50 \mathrm{ml} \mathrm{CHCl}{ }_{3}$ and subjected to ultrasonication for $30 \mathrm{~min}$. An amount of PLA (predetermined in Table 1) was also dissolved in $400 \mathrm{ml} \mathrm{CHCl}_{3}$ with the aid of a mechanical stirrer at $500 \mathrm{r} / \mathrm{min}$. The dispersed P-TAB was mixed with the dissolved PLA under vigorous stirring for $2 \mathrm{~h}$. For samples containing WF, a predetermined quantity of homogenized WF was added in bits (Table 1) and stirred mechanically for $2 \mathrm{~h}$ to obtain homogenous PLA/P-TAB/WF composite mixture. The temperature of the PLA/P-TAB/WF composite mixture was increased to $50^{\circ} \mathrm{C}$ for some

Table 1. P-TAB and wool fiber (WF) loading.

\begin{tabular}{|l|c|c|c|}
\hline \multicolumn{1}{|c|}{ Sample } & $\begin{array}{c}\text { PLA } \\
{[\%]}\end{array}$ & $\begin{array}{c}\text { P-TAB } \\
{[\%]}\end{array}$ & $\begin{array}{c}\text { (WF) } \\
{[\%]}\end{array}$ \\
\hline Neat PLA & 100 & - & - \\
\hline PLA/P-TAB & 97 & 3 & - \\
\hline PLA/P-TAB/WF 3\% & 92 & 3 & 5 \\
\hline PLA/P-TAB/WF 5\% & 87 & 3 & 10 \\
\hline PLA/P-TAB/WF 10\% & 77 & 3 & 20 \\
\hline
\end{tabular}

of the solvent to evaporate. The PLA/P-TAB/WF composite mixture was cast into a mold and dried in an oven at $70^{\circ} \mathrm{C}$ for $24 \mathrm{~h}$ to remove the remaining solvent. The dried PLA/P-TAB/WF composites were again conditioned at $90^{\circ} \mathrm{C}$ for $12 \mathrm{~h}$ in a vacuum oven, crushed into pieces and homogenized for $15 \mathrm{~min}$ utes. The composite samples without WF were also treated similarly. The composites were pressed with an automatic hydraulic press at $180^{\circ} \mathrm{C}$ for $2 \mathrm{~min}$ at 10 bars and then degassed. The composite samples were then pressed again for the second time for 1 min at 15 bars at $180^{\circ} \mathrm{C}$ and then transferred to the cold part for final pressing for $1 \mathrm{~min}$. The molds are removed to obtain the standard samples. Neat PLA granules were also dissolved and pressed into standard samples using the same procedure. The samples used for the tensile test were prepared and pressed using the same method.

\subsection{Characterization}

FTIR spectrometer equipped with attenuated total reflection (ATR) accessory was used. The samples were scanned at $4 \mathrm{~cm}^{-1}$ after averaging 16 scans between $650-4000 \mathrm{~cm}^{-1} \cdot{ }^{1} \mathrm{H}$ and ${ }^{13} \mathrm{C}$ NMR spectra of P-TAB was recorded with AVANCE 300 Bruker spectrometer (Germany), using Pyridine- $\mathrm{d}_{5}$ as a solvent. A Mettler Toledo TGA/DSC 1 Star System, was used to study the thermal properties of P-TAB and PLA/ $\mathrm{P}-\mathrm{TAB} / \mathrm{WF}$ composites at $20^{\circ} \mathrm{C} / \mathrm{min}$ with air flow rate of $40 \mathrm{ml} / \mathrm{min}$ between $40-700^{\circ} \mathrm{C}$ and samples weight 4-5 mg. A Perkin Elmer DSC 800 instrument was used at a scanning rate of $10^{\circ} \mathrm{C} / \mathrm{min}$ under $\mathrm{N}_{2}$ atmosphere with samples (4-5 mg) heated from 30 to $200^{\circ} \mathrm{C}$ and cooled to $30^{\circ} \mathrm{C}$, after which second heating was applied following the same program. The degree of crystallinity $\left(\chi_{c}\right)$ was calculated based on $\Delta H_{\mathrm{m}}$ according to Equation (1):

$\chi_{\mathrm{c}}=\frac{\Delta H_{\mathrm{m}}}{\Delta H_{\mathrm{mp}}(1-x)} \cdot 100 \%$

where $\Delta H_{\mathrm{m}}$ is the melting enthalpy of neat PLA and PLA/P-TAB/WF composites, $\Delta H_{\mathrm{mp}}$ is the melting enthalpy of $100 \%$ crystalline PLA $(93.6 \mathrm{~J} / \mathrm{g})$, and $x$ is the FR/WF content [40].

A TESCAN VEGA 3 SEM was used to observe the fracture surface and the char residues at various magnifications after sputter coating with $\mathrm{Au}$. Residual chars of PLA/P-TAB/WF composites were scanned with laser power $532 \mathrm{~nm}$ with integration 
time between 4-50 ms using Bay Spec 3 in 1 Raman Microscope.

The UL-94 vertical flame test was done according to ASTM D3801 with sheet dimensions $130 \times 13 \times$ $3.2 \mathrm{~mm}^{3}$. The Limiting Oxygen Index (LOI) was determined according to ASTM D2863-97 with sample size $130 \times 6.5 \times 3 \mathrm{~mm}^{3}$ using ZR-1 Intelligent Oxygen Index Analyzer.

Cone Calorimeter (Fire Testing Technology Ltd., UK) was carried out according to ISO 5660-1 standard with square specimens $\left(100 \times 100 \times 3 \mathrm{~mm}^{3}\right)$. Samples were wrapped in $\mathrm{Al}$ foil and irradiated at an external heat flux of $35 \mathrm{~kW} / \mathrm{m}^{2}$. The fire performance index (FPI) was calculated using Equation (2):

$F P I=\frac{t_{\text {ign }}}{P H R R}$

where $t_{\text {ign }}$ is the time to ignition and PHRR is the peak heat release rate of PLA, PLA/P-TAB, and PLA/P-TAB/WF biocomposites. Similarly, the fire growth index was also determined according to Equation (3):

$F G I=\frac{P H R R}{t_{\mathrm{p}}}$

where $P H R R$ is the peak heat release rate and $t_{\mathrm{p}}$ is time to peak heat release of neat PLA, and PLA/ P-TAB, and PLA/P-TAB/WF biocomposites.

The mechanical property was carried out on INSTRON 5566 using $\pm 500 \mathrm{~N}$ load cell according to ASTM D882 - 12 standard at $5 \mathrm{~mm} / \mathrm{min}$ with five dumb-bell shaped specimens $\left(50 \times 4 \times 0.84 \mathrm{~mm}^{3}\right)$ for each composition.

\section{Results and discussion}

\subsection{Structural characterization P-TAB}

The FTIR spectra of P-TAB was taken, and the result is shown in Figure 2a. The small narrow absorption peaks around $3480 \mathrm{~cm}^{-1}$ are attributed to the stretching vibrations of the secondary amine $(\mathrm{N}-\mathrm{H})$, with its bending mode around $1598 \mathrm{~cm}^{-1}$. The peaks belonging to the aromatic ring modes appeared at 1620$1510 \mathrm{~cm}^{-1}$ [41]. The absorption band around 3050$2930 \mathrm{~cm}^{-1}$ corresponds to $\mathrm{C}-\mathrm{H}$ stretching vibrations with their bending mode at $1495 \mathrm{~cm}^{-1}$ in P-TAB. The absorption peak of the $\mathrm{P}=\mathrm{O}$ bond can be seen at $1183 \mathrm{~cm}^{-1}$ while the sharp peak at $946 \mathrm{~cm}^{-1}$ is ascribed to the stretching vibration of the $\mathrm{P}-\mathrm{N}$ bond in P-TAB $[42,43]$ with the prominent $\mathrm{C}-\mathrm{N}$ peak at $1389 \mathrm{~cm}^{-1}$. The $1 \mathrm{H}$ spectrum of P-TAB is shown in Figure $2 \mathrm{~b}$. The doublet around 9.25 and $9.23 \mathrm{ppm}$ together with the multiplet at 8.59-8.52 and 8.828.53 ppm belongs to the aromatic ring in $\mathrm{ABT}$, while the singlet shift around $9.15 \mathrm{ppm}$ could be attributed to the resonance vibrations of the hydrogen atom of the secondary amine in P-TAB. The ${ }^{13} \mathrm{C}$ NMR spectrum further confirms the success of the synthetic process by the count of the carbon atoms present in P-TAB (as shown in the experimental section) The ${ }^{1} \mathrm{H},{ }^{13} \mathrm{C}$ NMR and the presence of $\mathrm{P}-\mathrm{N}$ and $\mathrm{C}-\mathrm{N}$ peaks in FTIR spectra demonstrates that P-TAB was successfully synthesized.

\subsection{Thermal properties of P-TAB, WF, and its PLA biocomposites}

The thermal properties of P-TAB, WF, and PLA/ $\mathrm{P}-\mathrm{TAB} / \mathrm{WF}$ composites are presented in Figure 3.
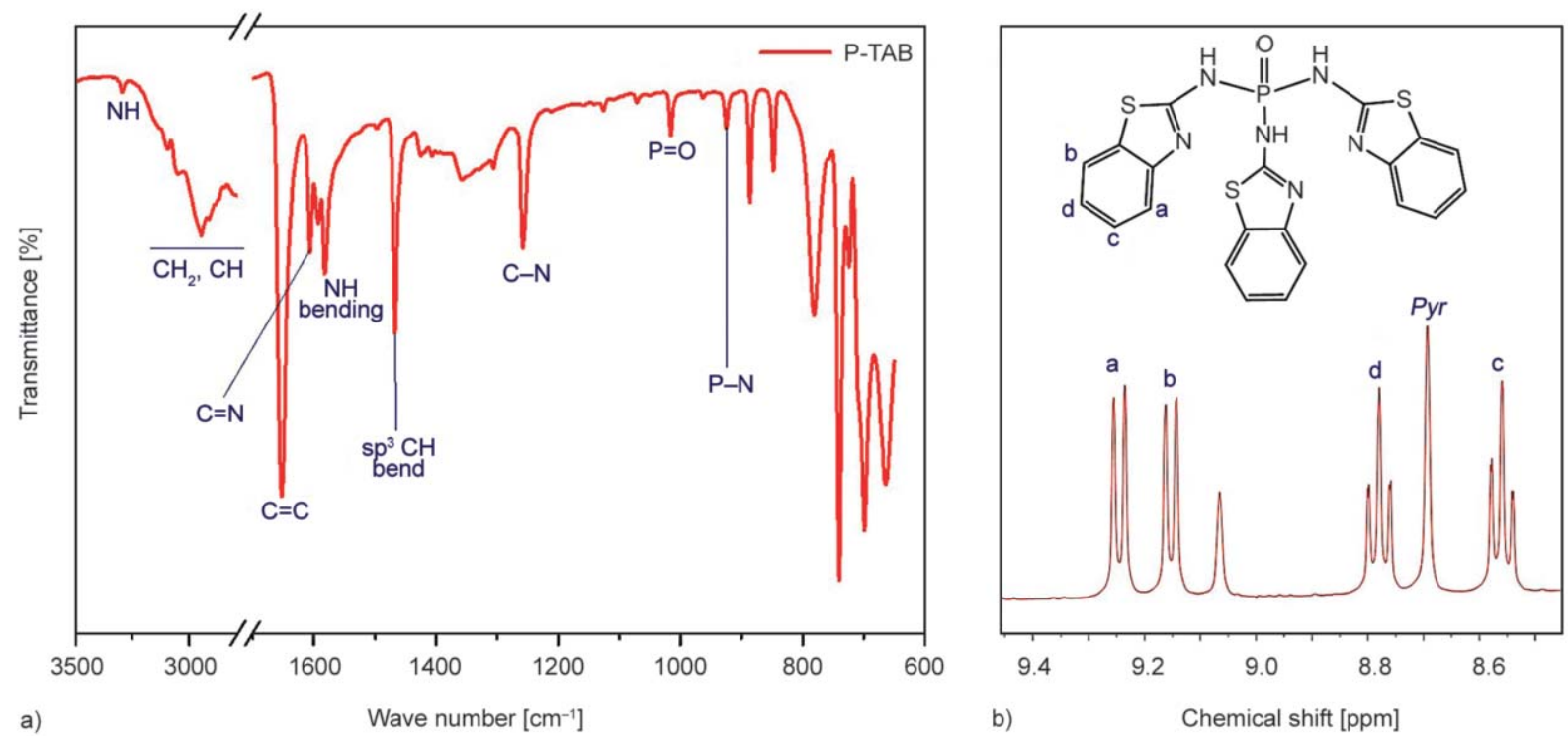

Figure 2. (a) FTIR spectra of P-TAB (b) ${ }^{1} \mathrm{H}$ NMR of P-TAB. 

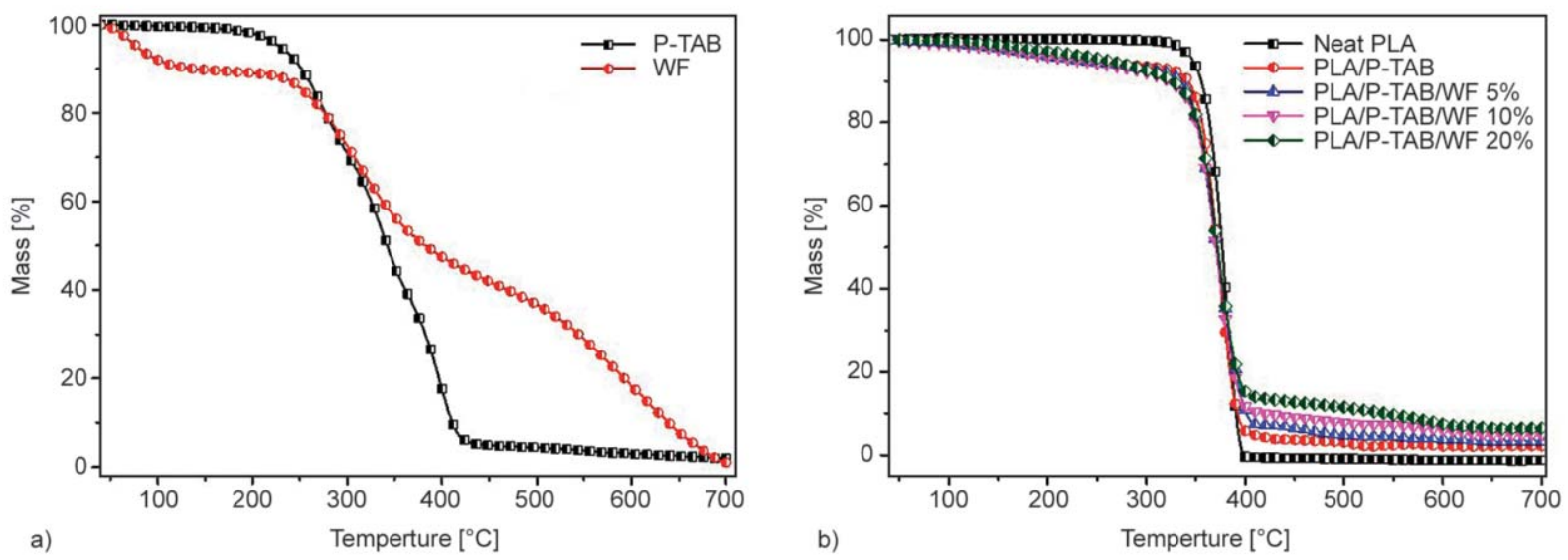

Figure 3. (a) TGA of P-TAB, and WF, (b) TGA of PLA, PLA/P-TAB, PLA/P-TAB/WF composites.

P-TAB presented three $T_{\text {-max }}$ decomposition peaks at 276,339 and $396^{\circ} \mathrm{C}$ respectively; while WF exhibited two major $T_{\text {-max }}$ peaks at $307,594^{\circ} \mathrm{C}$ (Figure 2, Table 2). Similarly, the onset decomposition temperature $\left(T_{-5 \%}\right)$ for P-TAB and WF at lower temperatures compared to neat PLA. The early mass loss for $\mathrm{P}-\mathrm{TAB}$ is ascribed to the loss of crystal water and possible decomposition by remnants of unreacted monomers. The first stage mass loss at $T_{\text {-max }}$ is due to the decomposition of the secondary amine groups. The second $T_{\text {-max }}$ peak is due to the release of PO radicals, sulfur and nitrogen oxides followed by the oxidation of unstable chars resulting from the carbonization process and subsequent formation of stable char residues. With regards to WF, the early mass loss below $150{ }^{\circ} \mathrm{C}$ is ascribed to the evaporation of adsorbed/crystal water and possible physical defects in the amorphous regions of the polymer chains during usage and homogenization [44]. The $T_{\text {-max }}$ decomposition peak around $307^{\circ} \mathrm{C}$ is attributed to the denaturing and degradation of the keratin molecules, followed by the cleaving of the disulfide bonds around $596^{\circ} \mathrm{C}$ and subsequent char formation [26]. The keratin structural protein in WFs contains high levels of sulfur and nitrogen, which creates char stability under high thermal conditions [45]. The maximum mass loss (M.M.L.) for WF is approximately twice that of P-TAB, which suggests high thermal stability of WF even at $T_{\text {-max }}$. However, the char yield for $\mathrm{P}-\mathrm{TAB}$ was higher $(2.05 \mathrm{wt} \%)$ compared to $\mathrm{WF}$ $(1.06 \mathrm{wt} \%)$. The marginally higher char residue of $\mathrm{P}$ TAB is due to the enhanced condensed phase mechanism of phosphorus. P-TAB (constant weight fraction 3\%) and WF (different weight fractions of 5, 10, $20 \%$ ) were mixed with PLA/P-TAB composites, and the thermal properties were studied. The PLA/P$\mathrm{TAB} / \mathrm{WF}$ composites presented early degradation with the increasing content of P-TAB and WF (Table 2).

Unlike P-TAB and WF additives alone, the composites (PLA/P-TAB/WF) displayed only one $T_{\text {-max }}$ peak at a relatively lower temperature compared with neat PLA (Table 2). The early $T_{-5}$ and $T_{\text {-max }}$ peaks are attributed to the early decomposition of the FR in the composites leading to the release of gaseous products which retire the degradation of PLA. The maximum mass change (M.M.C.) at $T_{\text {-max }}$ of neat PLA was higher $(-2.8 \%)$ compared PLA/P-TAB or

Table 2. TGA and DTG data of P-TAB, WF and PLA/P-TAB/WF composites.

\begin{tabular}{|l|c|c|c|c|c|}
\hline \multicolumn{1}{|c|}{ Sample } & $\begin{array}{c}\boldsymbol{T}_{\text {-5\% }} \\
{\left[{ }^{\circ} \mathbf{C}\right]}\end{array}$ & $\begin{array}{c}\boldsymbol{T}_{\text {-max }} \text { \% peak 1/2/3 } \\
{\left[{ }^{\circ} \mathbf{C}\right]}\end{array}$ & $\begin{array}{c}\boldsymbol{T}_{\text {-50 }} \\
{\left[{ }^{\circ} \mathbf{C}\right]}\end{array}$ & $\begin{array}{c}\text { M.C.C. } \\
{[\%]}\end{array}$ & $\begin{array}{c}\text { C.R. } \\
{[\mathbf{w t} \text { ] }]}\end{array}$ \\
\hline P-TAB & 229.5 & $276 / 339 / 396$ & 342.5 & -0.7 & 2.1 \\
\hline WF & 202.5 & $307 / 594$ & 385.1 & -0.3 & 1.1 \\
\hline PLA & 344.8 & 380.1 & 376.6 & -2.8 & 0.1 \\
\hline PLA/P-TAB & 261.6 & 373.6 & 372.4 & -2.2 & 1.0 \\
\hline PLA/P-TAB/WF 5\% & 214.2 & 372.2 & 371.6 & -1.6 & 3.3 \\
\hline PLA/P-TAB/WF 10\% & 213.6 & 371.0 & 372.9 & -1.7 & 5.0 \\
\hline PLA/P-TAB/WF 20\% & 212.4 & 370.3 & 373.9 & -1.8 & 6.7 \\
\hline
\end{tabular}

C.R. - Char Residue; M.M.C. - Maximum mass change at $T_{\text {-max }}$ 

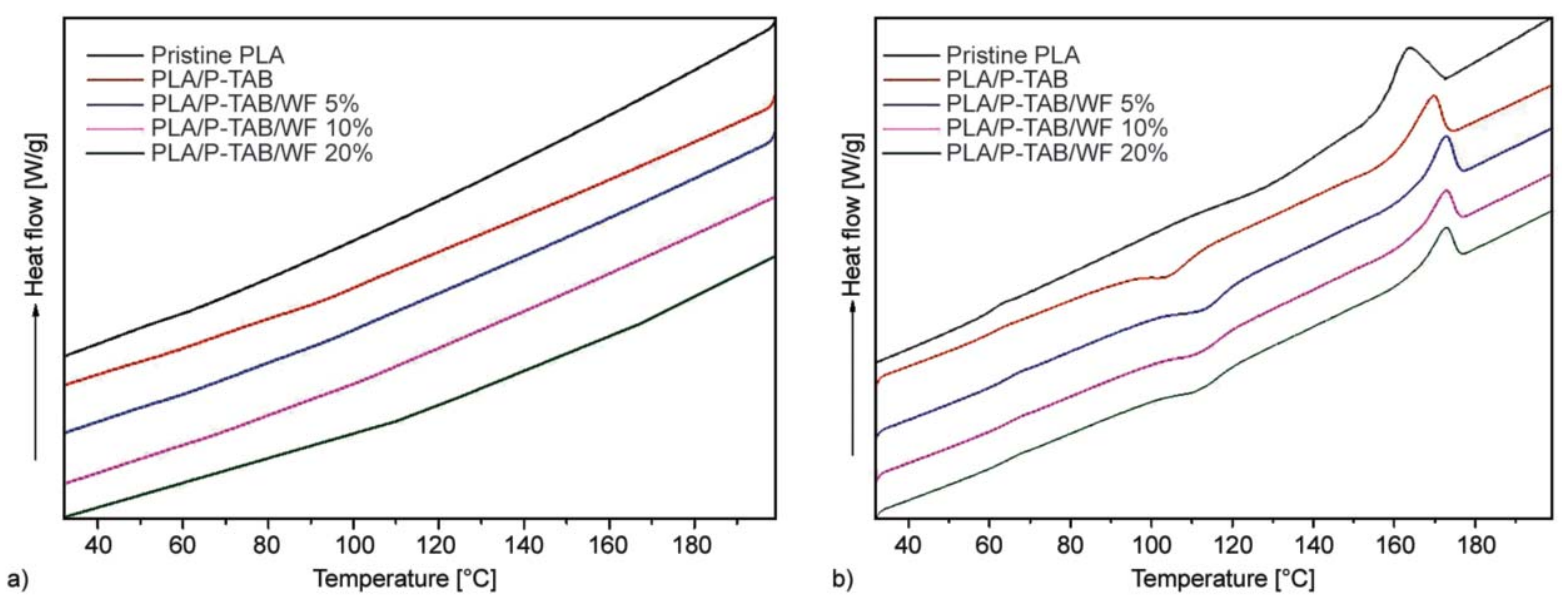

Figure 4. DSC curve of PLA, PLA/P-TAB, and PLA/P-TAP/WF composites: (a) cooling curve from 200 to $35^{\circ} \mathrm{C}$, and (b) second heating from 35 to $200^{\circ} \mathrm{C}$.

PLA/P-TAB/WF composites. With the increase in the content of WF to $5 \mathrm{wt} \%$ in the composite, the M.M.C. reduced to $-1.6 \%$. However, with further increases in WF content to 10 and $20 \mathrm{wt} \%$, the M.M.C. increased to ca. -1.7 and $-1.8 \%$ respectively. The char residue (C.R.) of PLA/P-TAB/WF composites increased marginally as the content of WF increases (see Table 2). It is evident from the increases in C.R. content that WF plays a vital role in the formation of char. Compact chars serve as a barrier to heat and reduce gaseous exchanges between the flame zone and the unburnt polymer composites [29]. Generally, the formation of carbonaceous intumescent char often shields and suppresses heat and mass loss rate of the composites and result in reductions in the flame spread and heat reduction [46].

The DSC curves of PLA, PLA/P-TAB, PLA/P-TAB/ WF composites are presented in Figure 4 with the related data in Table 3. Typically, no peaks were observed in the non-isothermal cooling process from the molten state as shown in Figure 4a due to the faster cooling rate and the stereochemistry of the PLA used. In the second heating scan, however, obvious exothermic peaks for PLA, PLA/P-TAB, PLA/ $\mathrm{P}-\mathrm{TAB} / \mathrm{WF}$ composites were detected. Also, the cold crystallization PLA/P-TAB reduced significantly compared to pristine PLA as shown in Table 3. However, with the introduction of WF at various quantities, the cold crystallization temperature increased. This phenomenon suggests that the polymer chains gain sufficient mobility to arrange themselves into ordered structure at lower temperature when P-TAB was introduced into PLA, hence the ability to crystallize at lower temperature than pristine PLA, whereas an additional energy (increased temperature) was required for the polymer chains to gain enough mobility to arrange themselves into similar ordered structure when WF was introduced at different loadings. Similarly, a minor increase in the melting temperature of PLA/P-TAB and its WF reinforced composites were observed (see Figure $4 \mathrm{~b}$ and Table 3 ). The marginal rise in melting temperature is due to the increased intrinsic defects in the crystal sizes of PLA caused by the presence of P-TAB and WF [37]. The percentage crystallinity $\left(\chi_{c}\right)$ for PLA reduced marginally with the introduction of P-TAB into PLA, however, when WF was introduced in various amounts, the $\chi_{c}$ decreased steadily as shown in Table 3 . The steady decrease in $\chi_{c}$ is due to the disruption of PLA crystals by P-TAB and WF $[36,38]$. With regards to the $T_{\mathrm{g}}$, no apparent changes were observed in WF reinforced PLA/FR composites and neat PLA

Table 3. Calorimetry data derived from the second heating measured after cooling from the melt.

\begin{tabular}{|l|c|c|c|c|c|c|}
\hline \multicolumn{1}{|c|}{ Sample } & $\begin{array}{c}\boldsymbol{T}_{\mathbf{g}} \\
{\left[{ }^{\circ} \mathbf{C}\right]}\end{array}$ & $\begin{array}{c}\boldsymbol{T}_{\mathbf{c}} \\
{\left[{ }^{\circ} \mathbf{C}\right]}\end{array}$ & $\begin{array}{c}\Delta \boldsymbol{H}_{\mathbf{c}} \\
{[\mathbf{J} / \mathbf{g}]}\end{array}$ & $\begin{array}{c}\boldsymbol{T}_{\mathbf{m}} \\
{\left[{ }^{\circ} \mathbf{C}\right]}\end{array}$ & $\begin{array}{c}\Delta \boldsymbol{H}_{\mathbf{m}} \\
{[\mathbf{J} / \mathbf{g}]}\end{array}$ & $\begin{array}{c}\chi_{\mathbf{c}} \\
{[\% \mathbf{\%}]}\end{array}$ \\
\hline PLA & 62.5 & 139.5 & 3.8 & 166.9 & 45.8 & 48.9 \\
\hline PLA/P-TAB & 61.6 & 98.2 & 22.4 & 169.9 & 44.2 & 47.2 \\
\hline PLA/P-TAB/WF 5 \% & 61.6 & 103.7 & 23.7 & 172.1 & 40.7 & 43.5 \\
\hline PLA/P-TAB/WF 10\% & 60.5 & 105.4 & 22.7 & 172.5 & 33.2 & 35.5 \\
\hline PLA/P-TAB/WF 20\% & 60.4 & 104.7 & 23.2 & 172.6 & 32.1 & 34.3 \\
\hline
\end{tabular}


(see Table 3), indicating the inconsequential effect of P-TAB or WF on the segmental mobility of PLA.

\subsection{Burning behavior}

The burning behavior of the samples were investigated by vertical burning tests (VBT), and the results are presented in Table 4 . When the samples were torched, the neat PLA dripped heavily (melt flame dripping) and burned the cotton placed beneath. The sample had sustained burning and therefore, resulted in no rating (NR). The PLA/P-TAB delayed the ignition time and had faster self-extinguishing time after the first and second flame applications with significantly fewer polymer drops (no flaming). Therefore, a V-1 rating was attained. Also, the flame was less fierce compared to neat PLA. The effect of WF on the burning resistance and melt dripping phenomenon was eminent in the PLA/P-TAB/WF composites because the dripping, and intensity of the flame reduced immensely but the flame timeout prolonged compared to the PLA/P-TAB composite, especially for the 5 and $10 \mathrm{wt} \% \mathrm{WF}$ loading. The phenomenon is due to extreme gas evolution of products like $\mathrm{NH}_{3}$, $\mathrm{CO}$, and $\mathrm{H}_{2} \mathrm{~S}$ by WF macromolecular chains during degradation into lighter products and volatile compounds which react with oxygen in the gas phase. Therefore, the samples could only achieve a V-2 rating. During the $10 \mathrm{~s}$ flame application, the PLA/ $\mathrm{P}-\mathrm{TAB} / \mathrm{WF}$ samples formed fragile residual char, which fell off due to the relatively prolonged burning. However, when the content of WF in PLA/ P-TAB composite increased to $20 \mathrm{wt} \%$, a heavy char formed at the tip of the polymer and impeded further combustion. The dripping phenomenon was curtailed, and a comparatively faster self-extinguishing time was attained as shown in Table 4. Therefore, a $\mathrm{V}-0$ rating was obtained. The enhanced charring effect of PLA/P-TAB/WF $20 \%$ composites is due to the combined effect of the sulfur, amino acids, nitrogen, and acidic carboxyl groups in WF and the phosphorus in P-TAB, which act predominantly in the condensed and the gas phases to reduce the exchange of pyrolysis gases and oxygen.

\subsection{Forced flame combustion}

The combustion behavior of PLA, PLA/P-TAB, and $\mathrm{PLA} / \mathrm{P}-\mathrm{TAB} / \mathrm{WF}$ composites were studied with cone calorimeter, and the results are shown in Table 5. The time to ignition (TTI), peak heat release rate (PHRR), total heat release (THR), total smoke release (TSR), $\mathrm{CO}$ and $\mathrm{CO}_{2}$ produced were assessed and the FPI and the FGI were determined. Neat PLA had a TTI of ca. $40 \mathrm{~s}$, a $P H R R$ of ca. $408 \mathrm{~kW} / \mathrm{m}^{2}$, and THR of ca. $49 \mathrm{MJ} / \mathrm{m}^{2}$. When $3 \mathrm{wt} \%$ P-TAB was introduced into PLA, the TTI increased from ca. 40 to $50 \mathrm{~s}$. With the addition of WF into PLA/P-TAB composite, the TTI decreased by $22.5 \%$. This trend continued with the increasing WF content in the composite until it reduced similarly to neat PLA. More so, significant reductions in PHRR was observed when $3 \mathrm{wt} \%$ P-TAB was added to PLA. Typically, ca. 35.5\% reductions in PHRR was observed whereas the THR reduced marginally by ca. $8.2 \%$ (Table 5 ). Subsequently, the HRR increases marginally with the introduction of WF, but the THR decreased continuously with WF loading (Table 5). The increase in PHRR suggests increasing fire intensity whereas the decrease in THR indicates a reduction in heat generated. Although the fire intensity increased, the total heat generated was low due to a shorter burning time. With regards to the mass loss of PLA and its FR composite, the various PLA/P-TAB/WF composites presented early mass loss similar to the phenomenon observed in TGA during combustion in CCT. The early mass loss leads to the release of inert nitrogen oxides, phosphorus radicals and material

Table 4. LOI and representative UL 94 data for PLA, PLA/P-TAB and PLA/P-TAB/WF composites.

\begin{tabular}{|c|c|c|c|c|c|}
\hline \multirow{3}{*}{ Sample } & \multirow{3}{*}{$\begin{array}{l}\text { LOI } \\
{[\%]}\end{array}$} & \multicolumn{4}{|c|}{ UL 94 Vertical test } \\
\hline & & \multicolumn{2}{|c|}{$\begin{array}{c}\text { Flame timeout } \\
{[\mathrm{s}]}\end{array}$} & \multirow[t]{2}{*}{ Ign. of cotton/dripping } & \multirow[t]{2}{*}{ Rating } \\
\hline & & $T_{1}$ & $T_{2}$ & & \\
\hline PLA & 19.5 & $12 \pm 1$ & $22 \pm 2$ & Yes/Yes (H.D.) & N. R. \\
\hline PLA/P-TAB & 29.8 & $3 \pm 1$ & $2 \pm 1$ & No/Yes (L.D) & $\mathrm{V}-1$ \\
\hline PLA/P-TAB/WF 5\% & 24.7 & $9 \pm 1$ & $12 \pm 1$ & No/Yes (L.D) & $\mathrm{V}-2$ \\
\hline PLA/P-TAB/WF $10 \%$ & 26.3 & $5 \pm 1$ & $6 \pm 1$ & No/Yes (L.D) & $\mathrm{V}-2$ \\
\hline PLA/P-TAB/WF $20 \%$ & 28.5 & $3 \pm 1$ & $2 \pm 1$ & $\mathrm{No} / \mathrm{No}$ & $\mathrm{V}-0$ \\
\hline
\end{tabular}

Note: H.D.: Heavy dripping, L.D.: Light dipping 
Table 5. Cone calorimetry data for P-TAB/PLA and P-TAB/PLA/WF composites at heat flux of $35 \mathrm{~kW} / \mathrm{m}^{2}$.

\begin{tabular}{|c|c|c|c|c|c|c|c|}
\hline Sample & $\begin{array}{c}\text { TTI } \\
{[\mathbf{s}]}\end{array}$ & $\begin{array}{c}\text { PHRR } \\
{\left[\mathrm{kW} / \mathrm{m}^{2}\right]}\end{array}$ & $\begin{array}{c}\text { THR } \\
{\left[\mathrm{MJ} / \mathrm{m}^{2}\right]}\end{array}$ & $\begin{array}{c}\text { PCOP } \\
{[\mathrm{g} / \mathrm{s}]}\end{array}$ & $\begin{array}{c}\mathrm{PCO}_{2} \mathrm{P} \\
{[\mathrm{g} / \mathrm{s}]}\end{array}$ & $\begin{array}{c}\text { AEHC } \\
{[\mathrm{MJ} / \mathrm{kg}]}\end{array}$ & $\begin{array}{c}\text { C.R } \\
{[w t \%]}\end{array}$ \\
\hline PLA & $40 \pm 2$ & $408 \pm 13$ & $49 \pm 3$ & $0.0031 \pm 0.001$ & $0.39 \pm 0.01$ & $16.7 \pm 2.1$ & $1.7 \pm 0.5$ \\
\hline PLA/P-TAB & $50 \pm 2$ & $264 \pm 6$ & $45 \pm 2$ & $0.0012 \pm 0.006$ & $0.26 \pm 0.02$ & $13.3 \pm 0.3$ & $6.7 \pm 0.6$ \\
\hline PLA/TAB/WF 5\% & $49 \pm 1$ & $277 \pm 9$ & $40 \pm 2$ & $0.0038 \pm 0.003$ & $0.27 \pm 0.04$ & $13.6 \pm 1.1$ & $11.2 \pm 0.4$ \\
\hline PLA/P-TAB/WF $10 \%$ & $48 \pm 2$ & $290 \pm 12$ & $34 \pm 1.2$ & $0.0050 \pm 0.002$ & $0.29 \pm 0.05$ & $14.8 \pm 1.6$ & $16.4 \pm 0.1$ \\
\hline PLA/P-TAB/WF $20 \%$ & $40 \pm 2$ & $302 \pm 19$ & $28 \pm 1.5$ & $0.0044 \pm 0.004$ & $0.30 \pm 0.05$ & $15.1 \pm 1.2$ & $21.3 \pm 0.2$ \\
\hline
\end{tabular}

C.R.: Char residue

charring by the WF to increase char production. However, the mass loss rate reduced and eventually became stable after the $180 \mathrm{~s}$ resulting in a steady increase in char residue with the increasing content of WF. Inopportunely, the char residues appeared frail and therefore was not be able to serve as a complete protective barrier to insulate the underlying polymer from further burning, hence increase in PHRR - although the THR reduced.

The presence of most FRs in polymers results in increased $\mathrm{CO}, \mathrm{CO}_{2}$, dioxins, $\mathrm{HCN}$ production during combustion [47]. The peak $\mathrm{CO}_{2}$ and $\mathrm{CO}$ produced during the combustion process are presented in Table 5. The $\mathrm{CO}_{2}$ production followed a similar trend to the PHRR due to the high conversion of partial oxidization product $(\mathrm{CO})$ to full oxidization product $\left(\mathrm{CO}_{2}\right)$ [42]. The $\mathrm{CO}$ production for FR PLA occurred mainly in the first 25 to $50 \mathrm{~s}$ with the PLA/P-TAB and PLA/P-TAB/WF composites having the lowest PCOP. However, towards the end of the combustion process (around 180-250 s), the CO production for PLA/ $\mathrm{P}-\mathrm{TAB}$ and PLA/P-TAB/WF composites increased marginally compared to the neat PLA due to smoldering resulting from incomplete combustion due to the condensed phase mechanism of P-TAB and conversely, the extreme gas phase mechanism of WF. The increased char residue induced by WF wasn't compact enough to reinforce the condensed phase chemistry of phosphorus, thus resulting in the evolution of a higher $\mathrm{CO}$.

Effective heat of combustion is the measure of the amount of heat released from a burning material per unit of sample burned during combustion in the cone calorimeter test. Low average effective heat of combustion values usually indicates a delay in ignition times and subsequent improvement in fire safety of polymeric materials. PLA/P-TAB had the lowest AEHC as shown in Table 5. When WF was introduced, the AEHC increased marginally. It is imperative to state that PLA/P-TAB alone improved the fire safety of the composites compared to PLA/
P-TAB/WF composites. However, generally, the AEHC of PLA/P-TAB/WF was lower than neat PLA - indicating a general FR efficiency of the phosphorus/WF system in improving the fire safety of PLA.

Figure 5 shows the FPI and the FGI of pristine PLA, PLA/P-TAB, and PLA/P-TAB/WF composites. Higher FPI and lower FGI values relate to enhanced fire safety for polymeric materials. Typically, the introduction of $3 \mathrm{wt} \%$ P-TAB into PLA led to a significant increase in FPI. When $5 \mathrm{wt} \% \mathrm{WF}$ was introduced, the FPI decreased from 0.189 to $0.177 \mathrm{~s} \cdot \mathrm{m}^{2} / \mathrm{kW}$. As the content of WF increased further to 10 and $20 \mathrm{wt} \%$ in the composites, the FPI decreases steadily to 0.167 and $0.132 \mathrm{~s} \cdot \mathrm{m}^{2} / \mathrm{kW}$. Despite the obvious decreases resulting from the increasing WF content in PLA/P-TAB, the $20 \mathrm{wt} \% \mathrm{WF}$ loading is $34.7 \%$ higher than that of neat PLA - indicating increased fire safety by the PLA/P-TAB/WF composites. In the same way, the FGI value for PLA/P-TAB composite decreased by $38.2 \%$, however, with the introduction of $5 \mathrm{wt} \% \mathrm{WF}$, the FGI declined to $31.7 \%$, signifying increased fire risk compared to PLA/P-TAB composite. When the content of WF in PLA/P-TAB composite increased to 10 , and $20 \mathrm{wt} \%$, the FGI values

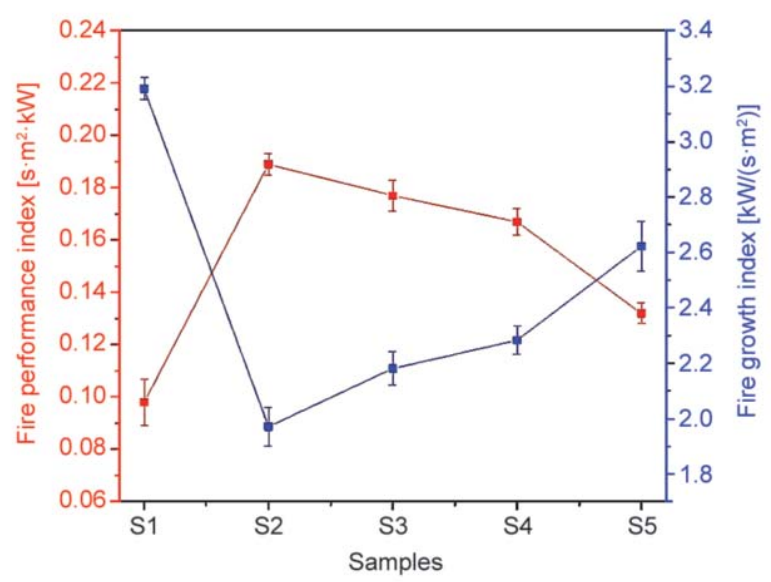

Figure 5. FGI/FPI of PLA, PLA/P-TAB and PLA/P-TAB/ WF composites (SI: Pristine PLA, S2: PLA/PTAB, S3-5: various WF loading in PLA/P-TAB composites). 
decreased further to 28.5 and $17.8 \%$ respectively. This phenomenon is consistent with the trend observed in PHRR. The presence of WF in PLA/P-TAB composites catalyzes early combustion and intensifies fire growth but leads to faster self-extinguishment, and at the same time reduces heat generation and stops melt dripping. It is important to state that despite the worsening FGI value because of WF addition, the composites polymers showed improved flame retardancy compared to neat PLA.

\subsection{Residual char analysis}

The microstructure of the char residues after the cone calorimeter test (CCT) were studied to understand the effects of WF and P-TAB on the composite's char formation, and its correlation with the FR trend observed in CCT, LOI, and UL 94 tests. The SEM micrographs shown in Figure 6. Neat PLA had less residue (predominantly made up of soot) while

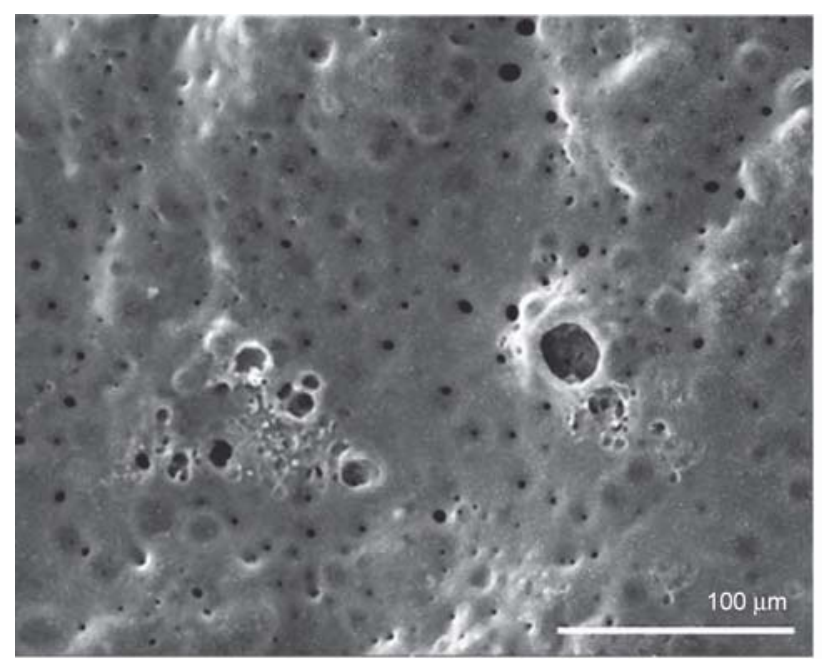

a)

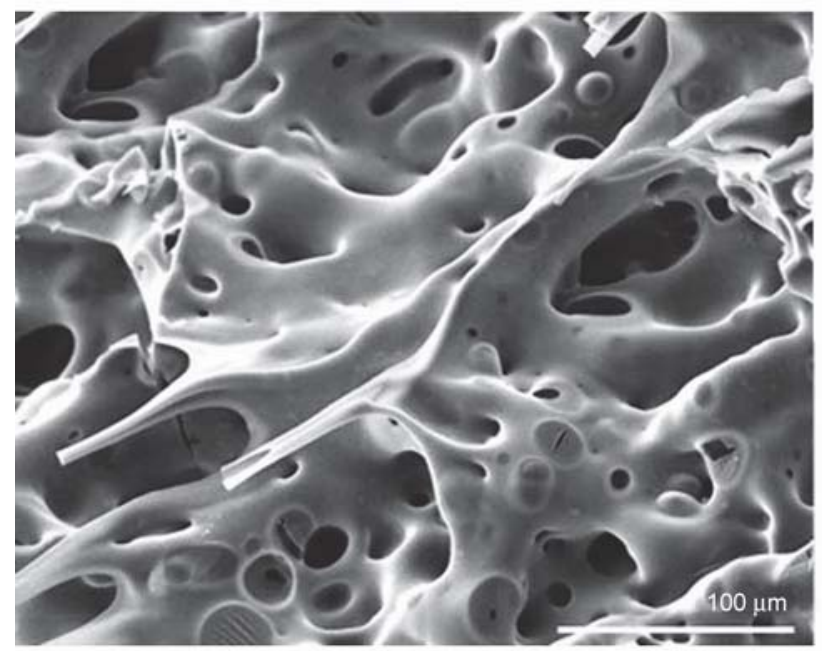

c)
PLA/P-TAB composite had a significant amount of char residue after combustion. The influence of WF on intumescent char formation was observed with the increasing WF content. The charring effect of $\mathrm{PLA} / \mathrm{P}-\mathrm{TAB} / \mathrm{WF}$ composites is due to the sulfur and amino acids in WF and P-TAB, in addition to the formation of phosphoric acids and the sulfonic groups during the endothermal decomposition process [29]. From the SEM image of PLA/P-TAB shown in Figure $6 \mathrm{a}$, a condensed char structure that can effectively reduce the diffusion of organic volatiles and heat can be observed, although it contains some nano-size pores/bubbles. Conversely, a more porous, less compact char structure with micron-sized fissures can be observed in the PLA/P-TAB/WF composites. The many fissures are obviously detrimental to fire growth and gaseous/smoke control because they could effectively serve as a diffusion channel for oxygen entry into the flame zone, and the release of pyrolysis

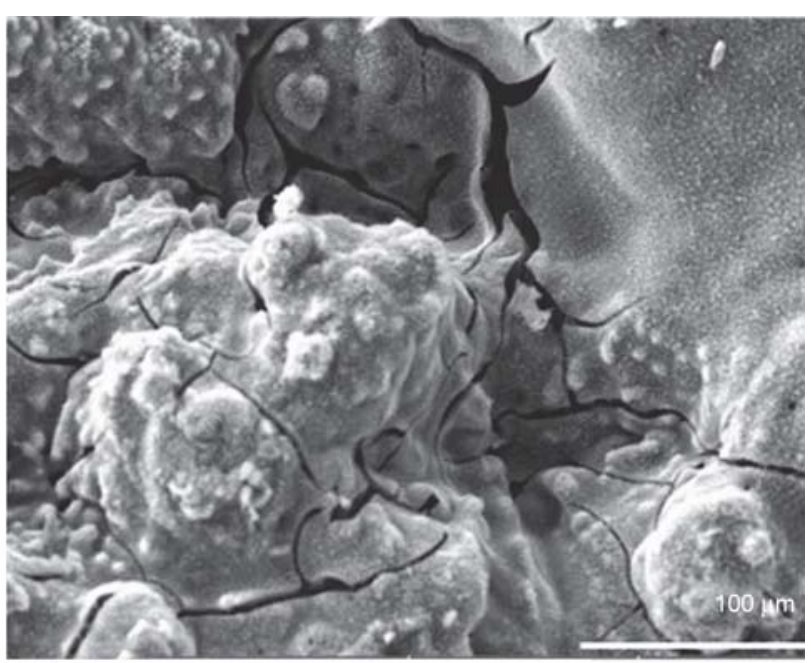

b)

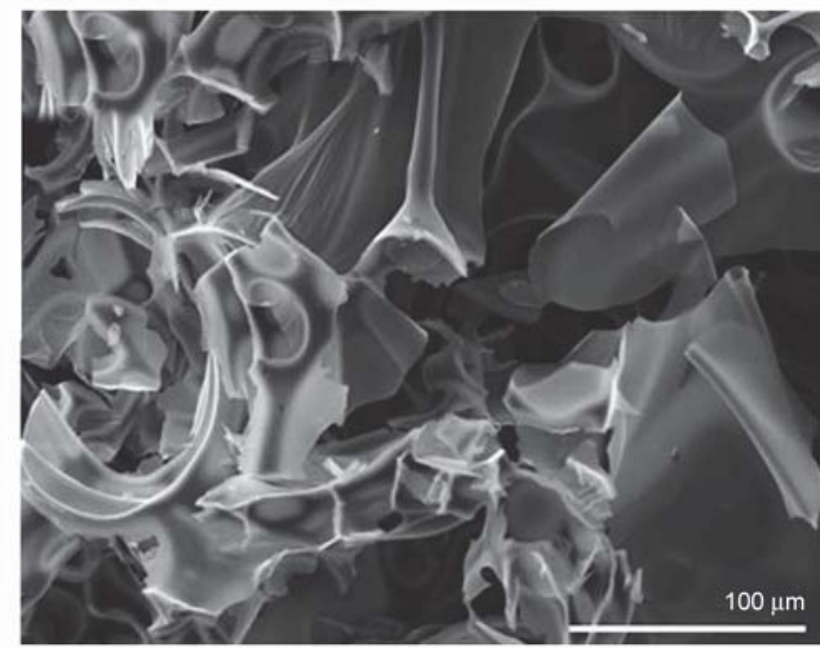

d)

Figure 6. SEM images of: (a) PLA/P-TAB, (b) PLA/P-TAB/WF 5\%, (c) PLA/P-TAB/WF 10\% and (d) PLA/P-TAB/WF $20 \%$ composites. 
products as well as aid heat exchanges between the flame zone and the underlying polymer. This phenomenon could result in increased heat release and fire growth. The porous char structure is attributed to the fragile mechanical resistance of the WF chars. This phenomenon is consistent with the increased $\mathrm{HRR}, \mathrm{COP} \mathrm{CO}_{2} \mathrm{P}$, FPI and FGI values observed in the cone calorimeter test with the increasing WF content.

The FTIR spectra of the residual chars were taken after CCT, and the results are shown in Figure 7. Peaks corresponding to $\mathrm{CH}$ vibrations can be found around $2921-2847 \mathrm{~cm}^{-1}$. The peaks around 1575 $1440 \mathrm{~cm}^{-1}$ relate to vibrations of heteroatomic species of decomposed aromatic rings in P-TAB. The distinct peaks around $1452-1428 \mathrm{~cm}^{-1}$ are attributed to $\mathrm{C}-\mathrm{O}$ and $\mathrm{C}=\mathrm{O}$ vibrations resulting from the decomposition products of PLA, P-TAB, and WF, while the peak at $1172 \mathrm{~cm}^{-1}$ relates to vibrations of tertiary amide resulting from the decomposition of the proteins from WF. The absorption bands at 1132 and $903 \mathrm{~cm}^{-1}$ are attributed to the stretching vibrations of $\mathrm{P}=\mathrm{O}$ and $\mathrm{P}-\mathrm{N}$ groups respectively, while the peak at $1018 \mathrm{~cm}^{-1}$ indicates the existence of $\mathrm{S}=\mathrm{O}$ groups in the char residue.

Raman spectra of PLA/P-TAB and PLA/P-TAB/WF residual chars are shown in Figure 7 . The $G$ band $\left(1600 \mathrm{~cm}^{-1}\right)$ relates to the in-plane vibrations of graphite carbons while the D band at $1338 \mathrm{~cm}^{-1}$ indicates to the presence of amorphous carbons [48]. The area of $\mathrm{D}$ divided by $\mathrm{G}\left(I_{\mathrm{D}} / I_{\mathrm{G}}\right)$ relates to the extent of graphite or amorphous content present in the residual chars [49]. Mostly, higher $I_{\mathrm{D}} / I_{\mathrm{G}}$ values indicate the presence of more amorphous chars, while the reverse is an indication of more graphite chars [50]. PLA/P-TAB had the lowest $I_{\mathrm{D}} / I_{\mathrm{G}}$ value with the $\mathrm{P}-\mathrm{TAB} / \mathrm{WF} 20 \%$ having the highest $I_{\mathrm{D}} / I_{\mathrm{G}}$ value (see Figure $7 b$ ). The phenomenon suggests an increase in amorphous char content after the introduction of WF. The increasing amorphous contents decrease the thermal stability/rigidity of the residue char which can allow for the exchange of organic volatiles and oxygen in the flame zone. Such occurrence resulted in increased fire growth rate and the high PHRR observed from CCT. The presence of heteroaromatic elements in the residual char is confirmed by the shoulder peaks around 755 and $1155 \mathrm{~cm}^{-1}$ which are attributed to $\mathrm{C}-\mathrm{N}$ and remnants of heteroaromatic species in the aromatic ring of $\mathrm{P}-\mathrm{TAB}$.

Based on the macro/microstructure, FTIR and the Raman spectra, the FR mechanism can be attributed to the condensed phase FR actions of phosphorusnitrogen-sulfur moieties in P-TAB and the predominantly gas phase inhibition of WF [51-53]. During combustion, the $\mathrm{N}-\mathrm{S}$ moieties degenerate into nitrogen and sulfur oxides that dilute the combustible gases [54]. In addition, the phosphorus moiety generates phosphorus radicals that suppress the evolution of volatile radicals while at the same time acting in the condensed phase to promote char formation. Also, the sulfur component in both P-TAB and WF contribute to the FR action by forming sulfonic acids in the flame when water is produced, in addition to the hydrolytic scissions of keratin polypeptides in WF. During endothermic decomposition of WF, the macromolecular chains decomposed into lighter
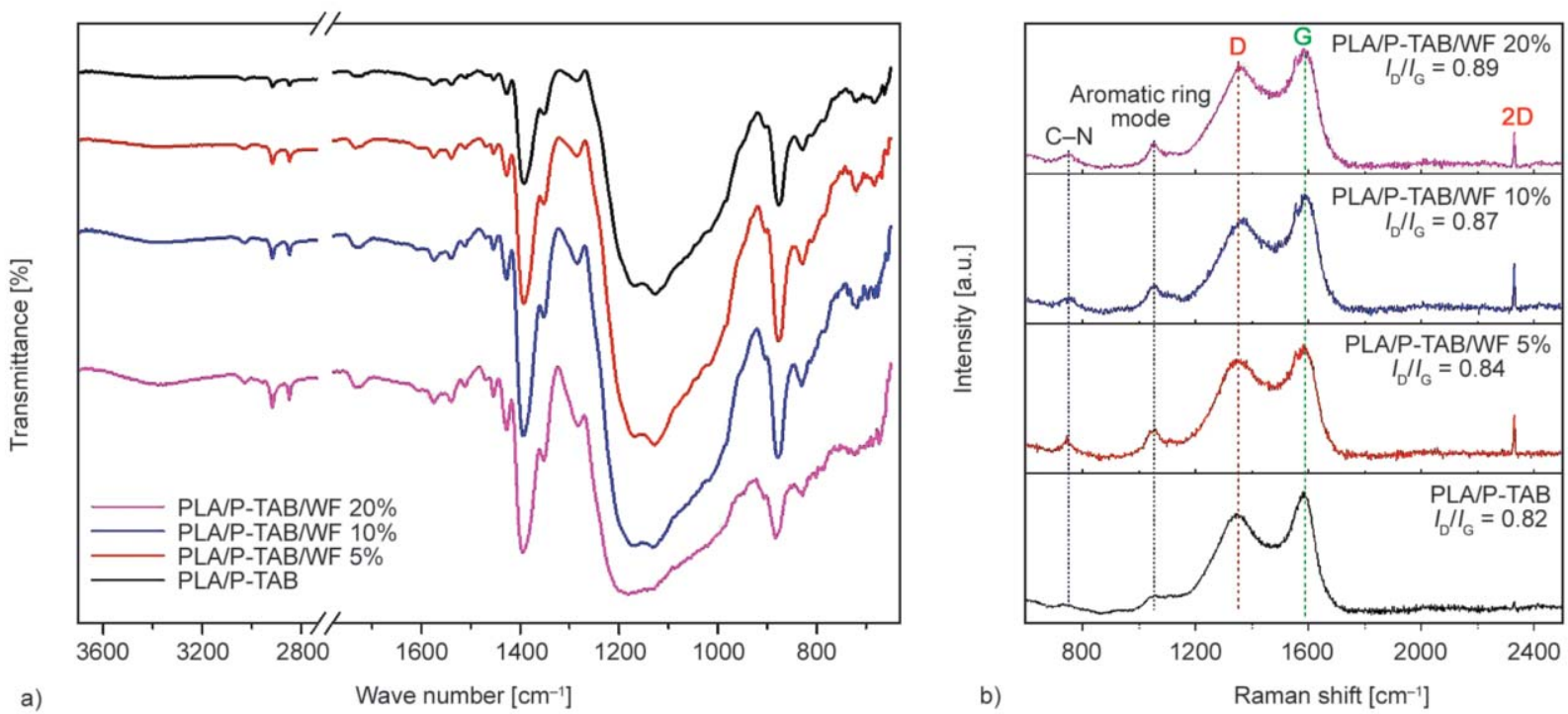

Figure 7. (a) FTIR spectra, and (b) Raman spectra of char residues after CCT. 
products and volatile compounds like $\mathrm{NH}_{3}, \mathrm{CO}$, and $\mathrm{H}_{2} \mathrm{~S}$ that react with oxygen in the gas phase, resulting in various oxidation products [55]. These processes lead to the formation of crosslinked char layers in the condensed phase, however, not compact enough due to the excessive evolution of pyrolysis gases products from WF. As a result, the char generated is not compact enough to serve as a complete barrier to the suppression of other volatile pyrolysis products [51] during combustion; hence the increases in PHRR, $\mathrm{CO}$, and $\mathrm{CO}_{2}$.

\subsection{Pyrolysis gaseous product analysis}

The pyrolysis gaseous products of PLA, PLA/P-TAB, and PLA/P-TAB/WF biocomposites during the thermal degradation process were investigated by TGFTIR, and the results are presented in Figure 8 . The FTIR spectrum of PLA/P-TAB and PLA/P-TAB/WF PLA biocomposites did not show any noticeable difference from that of neat PLA, implying that similar volatile gases were released during the thermal degradation process. The gaseous absorption products unique to P-TAB or WF were not noticeable, possibly due to the overlapping of the absorptions bands from the pyrolysis products of PLA. From Figure 8a, the gaseous pyrolysis products unique to PLA occurred around 3506, 2900-3000, 2350, and 2114$2182 \mathrm{~cm}^{-1}$, which are attributed to the evolution of water, hydrocarbons, $\mathrm{CO}_{2}$ and $\mathrm{CO}$ respectively [56]. The absorbance around 1759 and $1100-1250 \mathrm{~cm}^{-1}$ are ascribed to carbonyl compounds and aliphatic ester groups respectively. Similar peaks were recorded for the PLA/P-TAB and PLA/P-TAB/WF 20\% composites but at reduced absorption intensities as shown in Table 6. An overall reduction of evolved gaseous products during pyrolysis were obtained by the composites compared to neat PLA. A slight increase in total evolved gaseous product for PLA/ $\mathrm{P}-\mathrm{TAB} / \mathrm{WF} 20 \%$ was observed similar to the phenomenon observed from CCT gaseous products characterization. A similar occurrence was observed in total hydrocarbons, carbonyl compounds, and $\mathrm{CO}$ with the introduction of WF as shown in Table 6. Generally, PLA/P-TAB gave the lowest pyrolysis gaseous products compared to neat PLA and PLA/ $\mathrm{P}-\mathrm{TAB} / \mathrm{WF}$ composites. When WF was introduced, a marginal increase in total hydrocarbons, carbonyl compounds, and $\mathrm{CO}$ was observed. This phenomenon is due to the increased gas phase mechanism of WF due to the abundant pyrolysis volatile products

Table 6. Absorbance intensities of pyrolysis products of PLA and composites at maximum decomposition temperature.

\begin{tabular}{|l|l|l|l|}
\hline \multicolumn{1}{|c|}{ Pyrolysis gases } & \multicolumn{1}{|c|}{$\begin{array}{c}\text { Neat PLA } \\
\text { [a.u.] }\end{array}$} & $\begin{array}{c}\text { PLA/P-TAB } \\
\text { [a.u.] }\end{array}$ & $\begin{array}{c}\text { PLA/P-TAB/WF 20\% } \\
\text { [a.u.] }\end{array}$ \\
\hline Carbonyl compounds & 9.22 & 5.51 & 7.75 \\
\hline Hydrocarbons & 0.203 & 0.130 & 0.558 \\
\hline Carbon monoxide & Peak $1=0.071$ & Peak $1=0.052$ & Peak $1=0.067$ \\
& Peak $2=0.012$ & Peak $2=0.016$ & 1.02 \\
\hline Total absorption & 1.28 & 0.81 & 0.023 \\
\hline
\end{tabular}

Note: Peak one and two occurred at approximately 19 minutes 36 seconds, and 48 minutes 46 seconds respectively during pyrolysis.
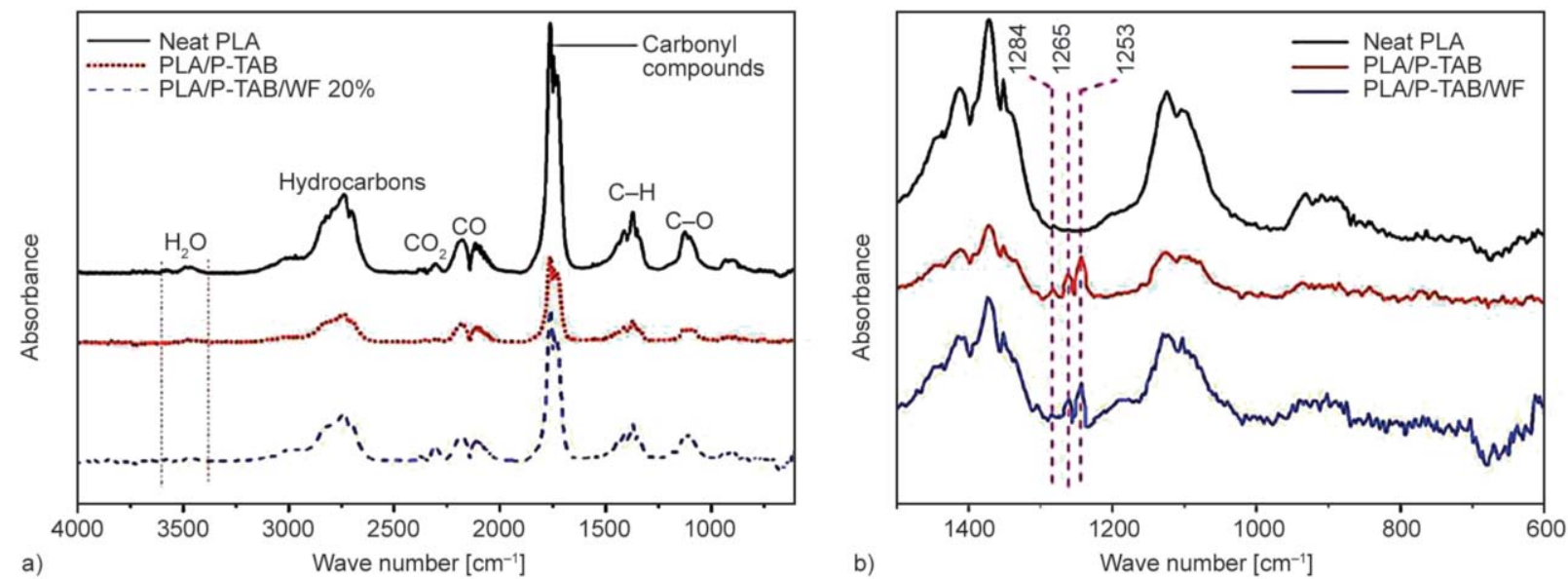

Figure 8. TG-IR absorbance spectra of pyrolysis products of: a) Neat PLA, PLA/P-TAB, PLA/P-TAB/WF 20\%, (b) phosphorus radicals evolved. 
of $\mathrm{NH}_{3}, \mathrm{CO}$, and $\mathrm{H}_{2} \mathrm{~S}$ macromolecular chains of WF during thermal decomposition and the porous nature of its residual chars as observed from the SEM micrograph in Figure 6c, 6d). Also, the absorption bands around 1284, 1265 and $1253 \mathrm{~cm}^{-1}$ in PLA/PTAB and PLA/P-TAB/WF $20 \mathrm{wt} \%$ composites are due to evolved pyrolysis gaseous products of phosphorus radicals such as $\mathrm{P}=\mathrm{O} \cdot, \mathrm{P}-\mathrm{O} \cdot$, and $\mathrm{P}-\mathrm{OH} \cdot$ fragments respectively; which are clearly missing from neat PLA [56] at the maximum decomposition temperature (Figure $8 b$ ).

\subsection{Mechanical properties}

FRs generally reduce the flammability of polymeric materials but at the same time can have a detrimental effect on the mechanical properties of composites, which might affect their engineering end use [4, 57]. As a result, the tensile properties of WF reinforced PLA/P-TAB composites were investigated, and the results are shown in Figure 9. The tensile strength,

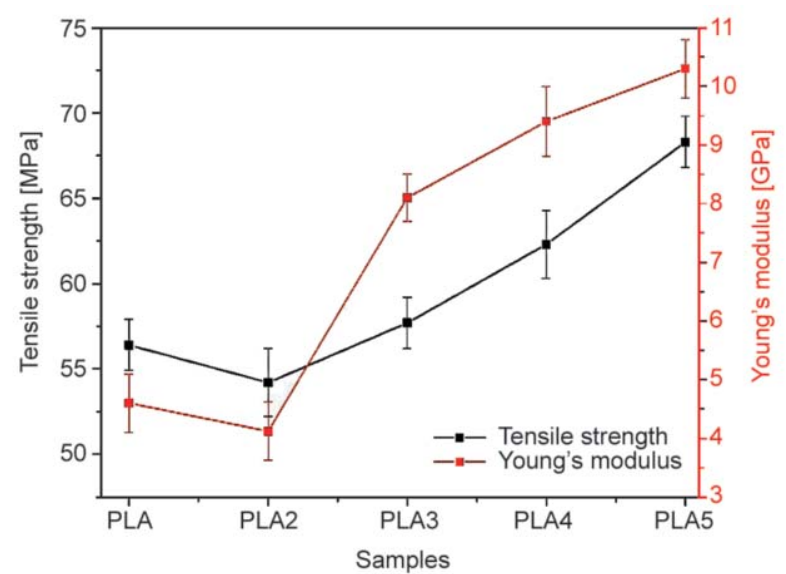

Figure 9. Tensile strength $v s$. Young's modulus of PLA, PLA/P-TAB, PLA/P-TAB/WF composites. (Note: PLA: neat PLA; PLA 2: PLA/P-TAB; PLA 3: PLA/P-TAB/WF 5\%; PLA 4: PLA/P-TAB/WF 10\%; PLA 5: PLA/P-TAB/WF 20\%.

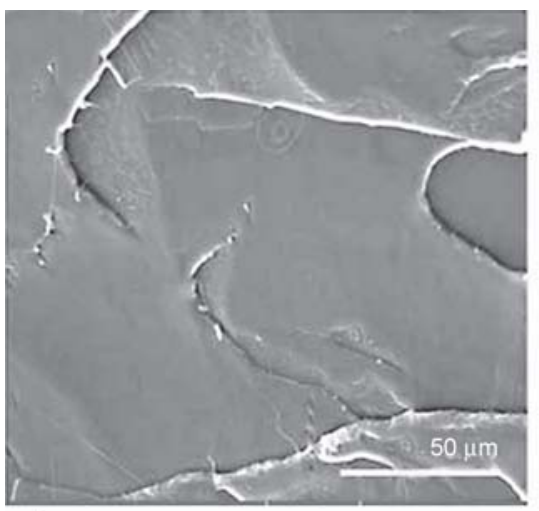

a)

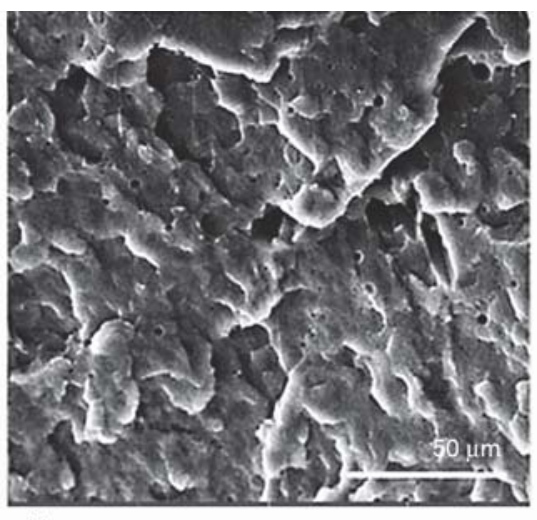

b) elongation at break and the Young's modulus reduced marginally by ca. $3.9,8.1$, and $4.5 \%$ respectively, with the addition of $3 \mathrm{wt} \%$ of P-TAB into PLA. When certain percentages of $\mathrm{WF}(5,10$, and $20 \mathrm{wt} \%)$ introduced into PLA/P-TAB composites, the tensile strength increased by ca. 3.5, 10.4, 26.6\% respectively. Similarly, the Young's modulus also increased considerably as shown in Figure 9. Nevertheless, the elongation at break of the PLA/P-TAB, and its WF composites reduced. The apparent reduction in elongation at break is due to the increased rigidity in the organic-inorganic interface between PLA, P-TAB, and WF. The increase in tensile strength by PLA/ $\mathrm{P}-\mathrm{TAB} / \mathrm{WF}$ composites can be attributed to the reinforcement effect of short WF in the composites.

To understand the reinforcement effect of WF in PLA/P-TAB composites, SEM micrographs of the specimen fracture surface (cross-section) after the tensile test was taken. Neat PLA, PLA/P-TAB, and PLA/TP-TAB/WF 20\% composites were studied, and the results are shown in Figure 10. Compared to neat PLA, PLA/P-TAB had micron size pores and interfacial defects. The interfacial defects and the micron size pores ultimately contributed to the reduced tensile strength, elongation at break, and Young's modulus observed in PLA/P-TAB composites. The pores created porous amorphous fractions within the PLA matrix which thus weakened the molecular cohesion of PLA chains in the matrix. For the WF reinforced PLA/P-TAB composites, the PLA matrix around WF appeared captured and dissipated earlier, thus transferring the load to WF in the matrix. Therefore, obvious fiber pulls/breaks could be observed, indicating the reinforcement effect of WF for PLA/P-TAB composites. However, the tensile strength and the elongation at break also depends mainly on the alignment of WF along the axis of the pull

Figure 10. SEM images of fracture surface from the tensile test: (a) neat PLA, (b) PLA/P-TAB, (c) PLA/P-TAB/WF 20\%. 
because the composite could break easily at its weakest point, which is the interfacial region between $\mathrm{WF}$ and the PLA/P-TAB matrix across the pulling direction. Depending on the priority of the specific mechanical properties desired (whether high mechanical strength to the detriment of elongation or vice versa), the PLA/TP-TAB/WF composites could be tailored to perform without compromising the FR properties. For instance, the elongation at break could be improved by the incorporation of a plasticizer while maintaining the excellent fire retardancy and high tensile strength.

\section{Conclusions}

The synthesis and application of phosphorus-nitrogen-sulfur containing FR (phenylphosphonic 3(2aminobenzothiazole) (P-TAB) and its combination with recycled short wool fibers for simultaneous FR and tensile strength enhancement of PLA biocomposites were reported. The composites were prepared by solvent mixing and compression molding and characterized extensively. FTIR, ${ }^{1} \mathrm{H}$ and ${ }^{13} \mathrm{C}$ NMR confirm the successful synthesis of phenylphosphonic 3(2-aminobenzothiazole) (P-TAB). The combination of $\mathrm{P}-\mathrm{TAB}$ with recycled wool fiber (WF) into PLA resulted in significant improvement in flame retardancy and tensile strength of the polymer composites (PC). Typically, the PHRR improved by ca. $35.5 \%$, the THR by ca. $8.2 \%$, and AEHC by ca. $24 \%$ with $3 \mathrm{wt} \%$ P-TAB loading. When WF was introduced, a marginal decline in PHRR and AEHC were observed. SEM and Raman spectroscopic study of the char residue revealed the development of more loosely bound amorphous char with micron size fissures with the increasing content of WF, which served as an escape route for heat and pyrolysis gases hence the increases in PHRR and AEHC. However, the WF reinforced PLA/P-TAB composite had improved FR performance compared to neat PLA due to apparent increases in THR, PHRR, FPI, and FGI compared to neat PLA. Also, a higher LOI value of $28.5 \%$ and a $\mathrm{V}-0$ rating was obtained when $20 \% \mathrm{WF}$ was introduced into PLA/P-TAB composites. DSC results showed a gradual reduction in the degree of crystallization with the increasing WF content. TG-FTIR study of evolved gaseous products indicates a significant reduction in total hydrocarbons, carbonyl compounds, and $\mathrm{CO}$ produced during thermal degradation.
More importantly, significant improvement in tensile strength and Young's Modulus was observed with the increasing WF content in PLA/P-TAB composites reaffirming the reinforcement effect of WF in preparing advanced functional composites for engineering applications.

\section{Acknowledgements}

The authors are thankful for the funding support of GRF project 15208015

\section{References}

[1] Ku H., Wang H., Pattarachaiyakoop N., Trada M.: A review on the tensile properties of natural fiber reinforced polymer composites. Composites Part B: Engineering, 42, 856-873 (2011).

https://doi.org/10.1016/j.compositesb.2011.01.010

[2] Dai Z., Yang Z., Chen Z., Zhao Z., Lou Y., Zhang Y., Liu T., Fu F., Fu Y., Liu X.: Fully biobased composites of an itaconic acid derived unsaturated polyester reinforced with cotton fabrics. ACS Sustainable Chemistry and Engineering, 6, 15056-15063 (2018). https://doi.org/10.1021/acssuschemeng.8b03539

[3] Yu T., Jiang N., Li Y.: Functionalized multi-walled carbon nanotube for improving the flame retardancy of ramie/poly(lactic acid) composite. Composites Science and Technology, 104, 26-33 (2014).

https://doi.org/10.1016/j.compscitech.2014.08.021

[4] Chen H., Wang J., Ni A., Ding A., Sun Z., Han X.: Effect of novel intumescent flame retardant on mechanical and flame retardant properties of continuous glass fibre reinforced polypropylene composites. Composite Structures, 203, 894-902 (2018). https://doi.org/10.1016/j.compstruct.2018.07.071

[5] Yallew T. B., Kumar P., Singh I.: Mechanical behavior of nettle/wool fabric reinforced polyethylene composites. Journal of Natural Fibers, 13, 610-618 (2016). https://doi.org/10.1080/15440478.2015.1093576

[6] Zini E., Scandola M.: Green composites: An overview. Polymer composites, 32, 1905-1915 (2011). https://doi.org/10.1002/pc.21224

[7] Zhao D., Zhou Z.: Applications of lightweight composites in automotive industries. in 'Lightweight materials from biopolymers and biofibers' (eds.: Yang Y., Xu H., Yu X.) American Chemical Society, Vol 1175, 143-158 (2014). https://doi.org/10.1021/bk-2014-1175.ch009

[8] Mochane M. J., Mokhena T. C., Mokhothu T. H., Mtibe A., Sadiku E. R., Ray S. S., Ibrahim I. D., Daramola O. O.: Recent progress on natural fiber hybrid composites for advanced applications: A review. Express Polymer Letters, 13, 159-198 (2019). https://doi.org/10.3144/expresspolymlett.2019.15 
[9] Al-Oqla F. M., Sapuan S. M.: Natural fiber reinforced polymer composites in industrial applications: Feasibility of date palm fibers for sustainable automotive industry. Journal of Cleaner Production, 66, 347-354 (2014).

https://doi.org/10.1016/j.jclepro.2013.10.050

[10] Thakur V. K., Thakur M. K., Gupta R. K.: Review: Raw natural fiber-based polymer composites. International Journal of Polymer Analysis and Characterization, 19, 256-271 (2014).

https://doi.org/10.1080/1023666X.2014.880016

[11] Negawo T. A., Polat Y., Buyuknalcaci F. N., Kilic A., Saba N., Jawaid M.: Mechanical, morphological, structural and dynamic mechanical properties of alkali treated Ensete stem fibers reinforced unsaturated polyester composites. Composite Structures, 207, 589-597 (2019). https://doi.org/10.1016/j.compstruct.2018.09.043

[12] Friedrich K., Almajid A. A.: Manufacturing aspects of advanced polymer composites for automotive applications. Applied Composite Materials, 20, 107-128 (2013). https://doi.org/10.1007/s10443-012-9258-7

[13] Koronis G., Silva A., Fontul M.: Green composites: A review of adequate materials for automotive applications. Composites Part B: Engineering, 44, 120-127 (2013).

https://doi.org/10.1016/j.compositesb.2012.07.004

[14] Irving P. E., Soutis C.: Polymer composites in the aerospace industry. Woodhead, Sawston (2014). https://doi.org/10.1016/C2013-0-16303-9

[15] Siengchin S.: Potential use of 'green' composites in automotive applications. Express Polymer Letters, 11, 600 (2017).

https://doi.org/10.3144/expresspolymlett.2017.57

[16] Kim N. K., Dutta S., Bhattacharyya D.: A review of flammability of natural fibre reinforced polymeric composites. Composites Science and Technology, 162, 6478 (2018).

https://doi.org/10.1016/j.compscitech.2018.04.016

[17] Yurddaskal M., Celik E.: Effect of halogen-free nanoparticles on the mechanical, structural, thermal and flame retardant properties of polymer matrix composite. Composite Structures, 183, 381-388 (2018).

https://doi.org/10.1016/j.compstruct.2017.03.093

[18] Couture A., Lebrun G., Laperrière L.: Mechanical properties of polylactic acid (PLA) composites reinforced with unidirectional flax and flax-paper layers. Composite Structures, 154, 286-295 (2016).

https://doi.org/10.1016/j.compstruct.2016.07.069

[19] Chow W., Teoh E., Karger-Kocsis J.: Flame retarded poly(lactic acid): A review. Express Polymer Letters, 12, 396-417 (2018).

https://doi.org/10.3144/expresspolymlett.2018.34

[20] Tawiah B., Yu B., Fei B.: Advances in flame retardant poly(lactic acid). Polymers, 10, 876/1-876/22 (2018). https://doi.org/10.3390/polym10080876
[21] Yang W., Tawiah B., Yu C., Qian Y-F., Wang L-L., Yuen A. C-Y., Zhu S-E., Hu E-Z., Chen T. B-Y., Yu B., Lu H-D., Yeoh G. H., Wang X., Song L., Hu Y.: Manufacturing, mechanical and flame retardant properties of poly(lactic acid) biocomposites based on calcium magnesium phytate and carbon nanotubes. Composites Part A: Applied Science and Manufacturing, 110, 227-236 (2018). https://doi.org/10.1016/j.compositesa.2018.04.027

[22] Patrucco A., Cristofaro F., Simionati M., Zoccola M., Bruni G., Fassina L., Visai L., Magenes G., Mossotti R., Montarsolo A., Tonin C.: Wool fibril sponges with perspective biomedical applications. Materials Science and Engineering: C, 61, 42-50 (2016).

https://doi.org/10.1016/j.msec.2015.11.073

[23] Chang H., Li Q., Xu C., Li R., Wang H., Bu Z., Lin T.: Wool powder: An efficient additive to improve mechanical and thermal properties of poly(propylene carbonate). Composites Science and Technology, 153, 119127 (2017).

https://doi.org/10.1016/j.compscitech.2017.10.012

[24] Forouharshad M., Montazer M., Moghaddam M., Saligheh O., Roudbari B.: Optimization of zirconium acetate on the flame retardant properties of wool. Journal of Applied Polymer Science, 125, 1261-1266 (2012). https://doi.org/10.1002/app.35353

[25] Basak S., Samanta K. K., Chattopadhyay S. K., Pandit P., Maiti S.: Green fire retardant finishing and combined dyeing of proteinous wool fabric. Coloration Technology, 132, 135-143 (2016).

https://doi.org/10.1111/cote. 12200

[26] Conzatti L., Giunco F., Stagnaro P., Patrucco A., Marano C., Rink M., Marsano E.: Composites based on polypropylene and short wool fibres. Composites Part A: Applied Science and Manufacturing, 47, 165-171 (2013).

https://doi.org/10.1016/j.compositesa.2013.01.002

[27] Salatino P., Di Benedetto A., Chirone R., Salzano E., Sanchirico R.: Analysis of an explosion in a wool-processing plant. Industrial and Engineering Chemistry Research, 51, 7713-7718 (2012).

https://doi.org/10.1021/ie2023614

[28] Kim N. K., Lin R. J. T., Bhattacharyya D.: Effects of wool fibres, ammonium polyphosphate and polymer viscosity on the flammability and mechanical performance of PP/wool composites. Polymer Degradation and Stability, 119, 167-177 (2015).

https://doi.org/10.1016/j.polymdegradstab.2015.05.015

[29] Gurunathan T., Mohanty S., Nayak S. K.: A review of the recent developments in biocomposites based on natural fibres and their application perspectives. Composites Part A: Applied Science and Manufacturing, 77, 125 (2015).

https://doi.org/10.1016/j.compositesa.2015.06.007

[30] Kilinc F. S.: Handbook of fire resistant textiles. Elsevier, Amsterdam (2013). 
[31] Hoang D., Kim J., Jang B. N.: Synthesis and performance of cyclic phosphorus-containing flame retardants. Polymer Degradation and Stability, 93, 2042-2047 (2008) https://doi.org/10.1016/j.polymdegradstab.2008.02.017

[32] Levchik S. V., Weil E. D.: A review of recent progress in phosphorus-based flame retardants. Journal of Fire Sciences, 24, 345-364 (2006). https://doi.org/10.1177/0734904106068426

[33] Weil E. D., Levchik S. V., Ravey M., Zhu W.: A survey of recent progress in phosphorus-based flame retardants and some mode of action studies. Phosphorus, Sulfur, and Silicon and the Related Elements, 144, 17-20 (1999). https://doi.org/10.1080/10426509908546171

[34] Perret B., Schartel B., Stöß K., Ciesielski M., Diederichs J., Döring M., Krämer J., Altstädt V.: Novel DOPO-based flame retardants in high-performance carbon fibre epoxy composites for aviation. European Polymer Journal, 47, 1081-1089 (2011). https://doi.org/10.1016/j.eurpolymj.2011.02.008

[35] Chen Y., Peng H., Li J., Xia Z., Tan H.: A novel flame retardant containing phosphorus, nitrogen, and sulfur. Journal of Thermal Analysis and Calorimetry, 115, 1639 1649 (2014). https://doi.org/10.1007/s10973-013-3461-0

[36] Zhao W., Li B., Xu M., Zhang L., Liu F., Guan L.: Synthesis of a novel flame retardant containing phosphorus and sulfur and its application in polycarbonate. Polymer Engineering and Science, 52, 2327-2335 (2012).

https://doi.org/10.1002/pen.23192

[37] Shamsuddin I. M., Jafar J. A., Shawai A. S. A., Yusuf S., Lateefah M., Aminu I.: Bioplastics as better alternative to petroplastics and their role in national sustainability: A review. Advances in Bioscience and Bioengineering, 5, 63-70 (2017). https://doi.org/10.11648/j.abb.20170504.13

[38] Jiang P., Gu X., Zhang S., Wu S., Zhao Q., Hu Z.: Synthesis, characterization, and utilization of a novel phosphorus/nitrogen-containing flame retardand. Industrial \& Engineering Chemistry Research, 54, 2974-2982 (2015). https://doi.org/10.1021/ie505021d

[39] Tawiah B., Yu B., Cheung W. Y., Chan S. Y., Yang W., Fei B.: Synthesis and application of synergistic azoboron-BPA/polydopamine as efficient flame retardant for poly(lactic acid). Polymer Degradation and Stability, 152, 64-74 (2018).

https://doi.org/10.1016/j.polymdegradstab.2018.03.018

[40] Valapa R. B., Pugazhenthi G., Katiyar V.: Effect of graphene content on the properties of poly(lactic acid) nanocomposites. RSC Advances, 5, 28410-28423 (2015).

https://doi.org/10.1039/C4RA15669B
[41] Morrill L. A., Kammeyer J. K., Garg N. K.: Spectroscopy 101: A practical introduction to spectroscopy and analysis for undergraduate organic chemistry laboratories. Journal of Chemical Education, 94, 15841586 (2017). https://doi.org/10.1021/acs.jchemed.7b00263

[42] Liu W., Chen D-Q., Wang Y-Z., Wang D-Y., Qu M-H.: Char-forming mechanism of a novel polymeric flame retardant with char agent. Polymer Degradation and Stability, 92, 1046-1052 (2007).

https://doi.org/10.1016/j.polymdegradstab.2007.02.009

[43] Shi X., Liao F., Ju Y., Dai X., Cao Y., Li J., Wang X.: Improving the flame retardance and melt dripping of poly(lactic acid) with a novel polymeric flame retardant of high thermal stability. Fire and Materials, 41, 362374 (2017). https://doi.org/10.1002/fam.2389

[44] Conzatti L., Giunco F., Stagnaro P., Capobianco M., Castellano M., Marsano E.: Polyester-based biocomposites containing wool fibres. Composites Part A: Applied Science and Manufacturing, 43, 1113-1119 (2012). https://doi.org/10.1016/j.compositesa.2012.02.019

[45] Liu X., Gu S., Xu W.: Thermal and structural characterization of superfine down powder. Journal of Thermal Analysis and Calorimetry, 111, 259-266 (2013). https://doi.org/10.1007/s10973-012-2202-0

[46] Yang W., Yang W-J., Tawiah B., Zhang Y., Wang L-L., Zhu S-E., Chen T. B. Y., Yuen A. C. Y., Yu B., Liu Y-F., Si J-Y., Hu E-Z., Lu H-D., Hu K-H., Chan Q. N., Yeoh G. H.: Synthesis of anhydrous manganese hypophosphite microtubes for simultaneous flame retardant and mechanical enhancement on poly(lactic acid). Composites Science and Technology, 164, 44-50 (2018). https://doi.org/10.1016/j.compscitech.2018.05.023

[47] Stec A. A., Hull T. R.: Assessment of the fire toxicity of building insulation materials. Energy and Buildings, 43, 498-506 (2011). https://doi.org/10.1016/j.enbuild.2010.10.015

[48] Shi Y., Yu B., Duan L., Gui Z., Wang B., Hu Y., Yuen R. K. K.: Graphitic carbon nitride/phosphorus-rich aluminum phosphinates hybrids as smoke suppressants and flame retardants for polystyrene. Journal of Hazardous Materials, 332, 87-96 (2017). https://doi.org/10.1016/j.jhazmat.2017.03.006

[49] Ferrari A. C., Robertson J.: Interpretation of Raman spectra of disordered and amorphous carbon. Physical Review B, 61, 14095-14107 (2000). https://doi.org/10.1103/PhysRevB.61.14095

[50] Wang G., Zhang J., Chang W., Li R., Li Y., Wang C.: Structural features and gasification reactivity of biomass chars pyrolyzed in different atmospheres at high temperature. Energy, 147, 25-35 (2018). https://doi.org/10.1016/j.energy.2018.01.025

[51] Green J.: Mechanisms for flame retardancy and smoke suppression - A review. Journal of Fire Sciences, 14, 426-442 (1996). https://doi.org/10.1177/073490419601400602 
[52] Qian X., Song L., Hu Y., Yuen R. K. K., Chen L., Guo Y., Hong N., Jiang S.: Combustion and thermal degradation mechanism of a novel intumescent flame retardant for epoxy acrylate containing phosphorus and nitrogen. Industrial and Engineering Chemistry Research, 50, 1881-1892 (2011).

https://doi.org/10.1021/ie102196k

[53] Granzow A.: Flame retardation by phosphorus compounds. Accounts of Chemical Research, 11, 177-183 (1978).

https://doi.org/10.1021/ar50125a001

[54] Hu X-P., Li W-Y., Wang Y-Z.: Synthesis and characterization of a novel nitrogen containing flame retardant. Journal of Applied Polymer Science, 94, 1556-1561 (2004).

https://doi.org/10.1002/app.20792
[55] Popescu C., Segal E., Iditoiu C.: A kinetic model for the thermal decomposition of wool. Thermochimica Acta, 256, 419-427 (1995).

https://doi.org/10.1016/0040-6031(94)02186-R

[56] Zhao P., Liu Z., Wang X., Pan Y-T., Kuehnert I., Gehde M., Wang D-Y., Leuteritz A.: Renewable vanillin based flame retardant for poly(lactic acid): A way to enhance flame retardancy and toughness simultaneously. RSC Advances, 8, 42189-42199 (2018). https://doi.org/10.1039/C8RA08531E

[57] Michler G. H., Balta-Calleja F. J.: Mechanical properties of polymers based on nanostructure and morphology. CRC Press, Boca Raton (2016).

https://doi.org/10.1201/9781420027136 